\title{
Short and long-term outcomes of the re-hepatectomies as part of multi-modal treatment of hepatic metastases from colo-rectal origin. Bi-institutional study
}

\author{
Resultados a corto y largo plazo de las rehepatectomías como parte del tratamiento \\ multimodal de las metástasis de origen colorrectal. Un estudio biinstitucional
}

\author{
Gustavo Nari ${ }^{*}$, Daniela Mariot ${ }^{1}$, Javier Góngora-Ortega ${ }^{2}$, Santiago López-Ben ${ }^{3}$, Maite Albiol ${ }^{3}$ and \\ Joan Figueras ${ }^{3}$ \\ ${ }^{1}$ Department of Surgery, Hospital Tránsito Cáceres de Allende, Córdoba, Argentine Republic; ${ }^{2}$ Biostatistics Unit, ISEA, Aguascalientes, Mexico; \\ ${ }^{3}$ Hepato-bilio-pancreatic Surgery Unit, Department of Surgery, Hospital Josep Trueta, Girona, Spain
}

\begin{abstract}
Introduction: A high percentage of patients undergoing hepatectomy for metastatic colorectal liver disease will have a recurrence. Of these, some can be subject to a new resection. The usefulness of repeated hepatectomy remains controversial. The aim of this study is to evaluate the results of short and long-term outcomes in repeated hepatectomies. Methods: They were re-analyzed 68 repeated hepatectomies from two institutions. Demographics, characteristics of metastatic disease and hepatic resections were analyzed. Types of complications, morbidity and mortality were also analyzed as survival and disease-free time. Some of the factors of poor prognosis mentioned in the literature were evaluated. Results: The analysis of short-term data showed no statistically significant differences between patients with first and repeated hepatectomy, except the percentage of postoperative biliary leakage $(p=0.001)$. The 1-year survival was similar while 3 and 5 years survival showed significant differences $(p=0.024$ and 0.004 , respectively). The factors of poor prognosis referred in the literature were not representative in this series. Conclusion: The short-term results of repeated hepatectomy are similar to those resected once. Long term result are inferior to other published series.
\end{abstract}

KEY WORDS: Hepatic metastases. Colo-rectal. Repeated hepatectomy. Survival. Prognostic factors.

\section{Resumen}

Introducción: Un alto porcentaje de pacientes que reciben una hepatectomía por metástasis de cáncer colorrectal presentarán recidiva hepática, y en algunas será posible una nueva resección. La utilidad de las hepatectomías repetidas continúa siendo discutida. Objetivo: Evaluar los resultados obtenidos a corto y largo plazo. Método: Fueron analizadas 68 rehepatectomías de dos instituciones. Se analizaron datos demográficos y características de la enfermedad metastásica y de las resecciones hepáticas. Los tipos de complicaciones y la morbimortalidad también fueron analizados, al igual que la supervivencia y el tiempo libre de enfermedad. Se evaluaron algunos de los factores de mal pronóstico mencionados en la literatura. Resultados: El análisis de los datos de corto plazo no mostró diferencias significativas entre los pacientes de primera hepatectomía y de hepatectomías repetidas, a excepción del porcentaje de fístulas biliares posoperatorias $(p=0.001)$. La supervivencia a 1 año es similar, mientras que a 3 y 5 años mostró diferencias significativas ( $p=0.024$ y 0.004, respectivamente). Los factores de mal pronóstico referidos en la literatura no fueron representativos en esta serie. Conclusión: Los

\author{
Correspondence: \\ ${ }^{*}$ Gustavo Nari \\ Servicio de Cirugía, Hosp. Tránsito Cáceres de Allende, \\ Buchardo 1200-1500, Córdoba, República Argentina \\ E-mail: gusnari@ hotmail.com
}

Cir Cir. 2018;86:306-313

Contents available at PubMed www.cirugiaycirujanos.com 
resultados a corto plazo de los pacientes con rehepatectomía son similares a los de aquellos resecados una vez. Los resultados a largo plazo de las rehepatectomías son inferiores a otros publicados.

PALABRAS CLAVE: Metástasis hepáticas. Colorrectales. Rehepatectomías. Sobrevida. Factores pronósticos.

\section{Introduction}

Colorectal cancer ranks third in frequency in the USA and it is the second cause of death from cancer in that country. Fifty percent of patients with colorectal cancer will develop hepatic metastasis in the course of the disease'.

The development of liver surgery, with important advances such as a greater understanding of the anatomy, anesthetic procedures, portal embolization, two-stage resections, the associating liver partition and portal vein ligation for staged hepatectomy (ALPPS) technique and radiofrequency, as well as the new chemotherapeutic agents ${ }^{2-11}$, have favored for the number of patients who undergo resection with curative intent to have increased.

Currently, hepatic resection continues to be the procedure that offers the best possibilities of cure to patients with liver metastases of colorectal origin, with a survival higher than $67 \%$ in well-selected cases ${ }^{7}$.

Fifty to $70 \%$ of patients who underwent hepatectomy for metastasis of colorectal origin will relapse from their liver disease, and $30-40 \%$ of them will do it in an oligometastatic form ${ }^{7,10-19}$. In these cases, re-hepatectomies, together with perioperative chemotherapy as part of a multimodal treatment, would improve survival and would achieve 5-year survival rates ranging from 21 to $88 \% \%^{7,20-25}$, although some authors consider that these procedures would have "marginal" effectiveness ${ }^{15}$.

New resections reach in some series $30 \%$ of all liver resections for colorectal metastases ${ }^{26}$. On the other hand, those patients with unresectable post-hepatectomy relapses would have a 5 -year survival rate of around $0 \%$.

The present work aims to evaluate the results obtained in the short and long-term in a pooled series of patients resected again, with the hypothesis that re-hepatectomies are beneficial for these patients.

\section{Method}

We analyze data of patients undergoing resection of hepatic metastases of colorectal origin in two centers between 1997 and 2013; the data were prospectively extracted from databases and retrospectively analyzed. Patients with two-stage hepatectomies were excluded from analysis. Demographic and clinicopathological characteristics were collected, as well as data related to hepatectomies. Intrahepatic relapse was identified with computed tomography; in some patients, positron emission tomography (PET) was used in the search for extrahepatic disease. All patients who received perioperative chemotherapy within the previous 10 years had a regimen based on oxaliplatin and irinotecan.

\section{Liver resections}

All patients in whom surgery could remove the entire hepatic tumor mass were considered resectable, regardless of the number and situation of the liver metastases. Major resection was defined as that which involved three or more consecutive segments of the Couinaud classification. The nomenclature used is the one proposed in Brisbane ${ }^{27}$. Hepatic parenchymal transection was performed by different procedures, which included the use of Kellyclasia, monopolar and bipolar scalpels, harmonic scalpels and cavitron ultrasonic surgical aspirator (CUSA). The liver resection time was measured in minutes from the beginning of the incision to the final closure of the skin. Portal vein occlusion was performed by embolization or ligation.

\section{Short-term results}

Postoperative mortality was considered when it occurred within the first 30 days, during hospitalization or at re-admission for complications inherent to surgery. Morbidity was defined as any adverse event inherent to the surgical procedure, and it was classified according to Dindo-Clavien proposal ${ }^{28}$. Liver failure was defined by the " $50-50$ " criterion ${ }^{29}$. Transfusions were measured in milliliters. Hospital stay was counted in days.

\section{Postoperative follow-up}

The patients were followed-up on a regular basis with laboratory controls, tumor markers and diagnostic imaging. Survival follow-up and control were carried out until death or until the date of last control in the office. Survival was calculated at 1,3 and 5 years. 


\section{Statistical analysis}

Categorical variables were compared with the chisquare test, and continuous variables with the ANOVA system. For survival analysis, the Kaplan-Meier test was used, and differences in survival curves were compared using the log-rank test. For statistical analysis, the SPSS system, version 20 (Chicago IL), was used. A p-value $<0.05$ was considered significant.

\section{Results}

From 1997 to 2013, 530 hepatectomies were performed, out of which 86 were excluded from this analysis because they were two-stage hepatectomies. Of the remaining 444 (study population), 68 were new resections for relapses and account for $15.3 \%$ of the series (Fig. 1).

The male gender was predominant, with no significant differences existing between those who underwent one hepatectomy and those that were resected again. Age did not show significant differences between the study groups either. Colon cancer was more common than rectal cancer, while Dukes C-type, pT3 and 4, and $\mathrm{n} 1$ and 2 tumors, were predominant in each group, with no significant differences existing (Table 1).

With regard to metastases, in $39.5 \%$ of the patients resected for a second time metastases were bi-lobar, their size was found to be larger than $3 \mathrm{~cm}$ in about one third and their number was less than 3 in the majority; both in these data and in the values of pre-hepatectomy tumor markers, there were no statistically significant differences (Table 2).

The resection margin was less than 1 centimeter, but larger than $50 \mathrm{~mm}$, both in the first and in the second hepatectomy. The existence of associated liver disease was similar, as it was the presence of extrahepatic disease (Table 2).

Although there were no significant differences in surgical time, transfusion requirements, portal embolization and in the number of minor resections, in the latter two there is a significant increase perceived in patients who were resected again (Table 2).

Hospital length of stay had a mean of 9.74 days for patients with one resection and 9.72 for those who had two, while morbidity was $44.35 \%$ and $38.88 \%$, respectively. Mortality showe4d no significant differences between study groups (Table 3).

Main complications were biliary fistula, liver failure, surgical wound infection, ascites, pneumopathy, intra-abdominal abscess and hemoperitoneum. Among all of them,

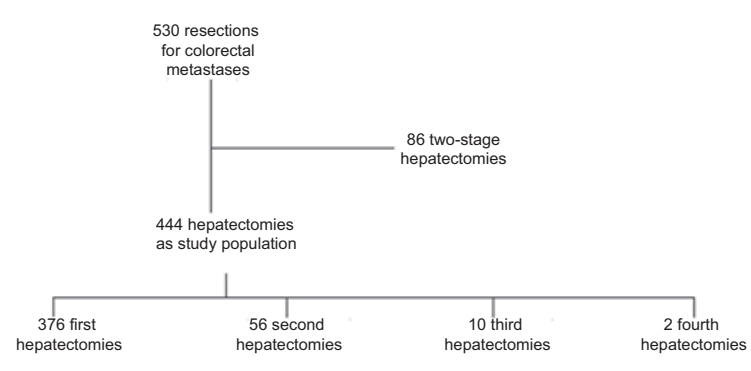

Figure 1. Liver resections' distribution.

the only complication that showed a statistically significant difference was biliary leak $(p=0.001$ ) (Table 3 ).

The severity of complications according to the Dindo-Clavien classification in each study group can be seen in table 4.

Figures 2, 3 and 4 show 1-, 3- and 5-year survival, respectively. One-year survival for the group with a second resection was $58.3 \%(p=0.223)$, 3-year survival was $18.5 \%(p=0.024)$ and 5 -year survival was $3.5 \%(p=0.004)$.

Some of the variables mentioned in the literature as factors for poor prognosis were analyzed, including rectal location of the primary tumor $(p=0.511)$, presence of extrahepatic disease $(p=0.444)$, bi-lobar localization ( $p=0.666)$, major resection $(p=0.286)$, margin smaller than $5 \mathrm{~mm}(p=0.057)$, transfusions $(p=0.350)$, presence of liver disease $(p=0.176)$ and having more than three lesions $(p=0.206)$, and none of them was shown to be a poor prognosis factor.

\section{Discussion}

In patients who experience liver relapse, re-hepatectomy, as part of a multimodal treatment would improve their survival. Five-year survival rates are reported to range from 21 to $88 \% \%^{7,20-25,30-34}$, although some authors consider that re-hepatectomies would have "marginal" effectiveness ${ }^{15}$.

Second resections reach in some series $30 \%$ of all liver resections for colorectal metastases ${ }^{26}$. In our series, and in coincidence with some authors, the percentage of re-hepatectomies was around 15\%". Minor resections were predominant, as reported by other authors, with a significant increase in second resections that almost reaches $80 \%$ in our series and that is consistent with the findings reported by Wichters et al. ${ }^{7}$, for whom only $17 \%$ were major hepatectomies.

On the other hand, we observed that $59.37 \%$ of patients who underwent a second hepatectomy were bearers of more than three metastases, which shows an expansion of the indications that aims at resecting 
Table 1. Demographic characteristics

\begin{tabular}{|c|c|c|c|c|c|}
\hline Variable & 1. hepatectomy & 2. hepatectomy & 3. hepatectomy & 4. hepatectomy & $p$ \\
\hline Male gender & $69.78 \%$ & $64.28 \%$ & $60 \%$ & - & 0.680 \\
\hline $\operatorname{Age}( \pm \mathrm{SD})$ & $63.98( \pm 10.466)$ & $63.87( \pm 8.299)$ & $62.10( \pm 8.316)$ & 73 & 0.771 \\
\hline Colon cancer & $65.86 \%$ & $65.90 \%$ & $77.7 \%$ & - & 0.785 \\
\hline Rectal cancer & $34.14 \%$ & $34.1 \%$ & $22.3 \%$ & $0 \%$ & \\
\hline Dukes A & $4.25 \%$ & $2.63 \%$ & $0 \%$ & $0 \%$ & 0.910 \\
\hline Dukes B & $23.75 \%$ & $28.94 \%$ & $12.5 \%$ & $0 \%$ & \\
\hline Dukes C & $71.98 \%$ & $68.42 \%$ & $87.5 \%$ & $12.5 \%$ & \\
\hline pT 1 and 2 & $9.86 \%$ & $17.07 \%$ & $0 \%$ & $0 \%$ & 0.562 \\
\hline pT 3 and 4 & $90.13 \%$ & $82.92 \%$ & $100 \%$ & $100 \%$ & \\
\hline NO & $33.55 \%$ & $34.14 \%$ & $22.22 \%$ & $0 \%$ & 0.260 \\
\hline $\mathrm{N} 1$ and 2 & $66.44 \%$ & $65.85 \%$ & $77.77 \%$ & $0 \%$ & \\
\hline
\end{tabular}

SD: standard deviation.

Table 2. Characteristics of metastases and hepatectomies

\begin{tabular}{|c|c|c|c|c|c|}
\hline Variable & 1. hepatectomy & 2. hepatectomy & 3. hepatectomy & 4. hepatectomy & p \\
\hline Bi-lobar metastases & $41.45 \%$ & $39.5 \%$ & $30 \%$ & - & 0.739 \\
\hline Extrahepatic disease & $19.58 \%$ & $13.63 \%$ & $20 \%$ & - & 0.767 \\
\hline Size $(\mathrm{cm})$ & 3.85 & 3.30 & 3.37 & 2.8 & 0.780 \\
\hline 1-3 metastases & $69.60 \%$ & $40.62 \%$ & - & - & 0.000 \\
\hline More than 3 metastases & $30.39 \%$ & $59.37 \%$ & - & - & \\
\hline Portal embolization & $10.62 \%$ & $21.81 \%$ & $11.1 \%$ & 0 & 0.119 \\
\hline Pre-hepatectomy CEA $( \pm$ SD) & $40.43( \pm 141.564)$ & $50.19( \pm 221.930)$ & $24.81( \pm 24.152)$ & 51.80 & 0.972 \\
\hline Pre-hepatectomy Ca19 $9( \pm$ SD $)$ & $76.58( \pm 241.432)$ & $142.05( \pm 431.4487)$ & $93.58( \pm 149.55)$ & 80.00 & 0.688 \\
\hline Minor resection & $60.32 \%$ & $78.57 \%$ & $90 \%$ & $100 \%$ & 0.14 \\
\hline Margin $(\mathrm{mm} \pm \mathrm{SD})$ & $0.84( \pm 1.163)$ & $0.96( \pm 1.232)$ & $0.21( \pm 0.280)$ & 0.00 & 0.339 \\
\hline Surgical time $(\min )( \pm \mathrm{SD})$ & $235.73( \pm 104.308)$ & $214.17( \pm 102.487)$ & $214.38( \pm 63.664)$ & 255.00 & 0.508 \\
\hline Liver disease & $5.22 \%$ & $6.89 \%$ & $11.11 \%$ & 0 & 0.879 \\
\hline
\end{tabular}

CEA: Carcinoembryonic antigen; SD: Standard deviation.

the entire hepatic tumor burden as long as it is technically possible ${ }^{7,34}$.

Both hospital stay and surgical time were similar and are consistent with observations published by different authors ${ }^{1,34}$.

With regard to short-term results, morbidity (38.8\%) is within the parameters reported in the literature , $, 8,13,30-32$. Types 2 and 3 of the Dindo-Clavien classification were the surgical complications that occurred more frequently, while in Jong et al. series $^{1}$, type 1 and 2 were the complications that predominated.
The incidence of biliary fistula in the first hepatectomy was similar to that reported by other authors ${ }^{8}$, with a higher percentage in the second hepatectomy, with the difference being statistically significant $(p=0.001)$; this data is not consistent with those reported in the literature ${ }^{7}$. Although in the rest of the measured parameters that could justify this increase (major resections, higher number of bi-lobar metastases, increase in the number of transfusions, etc.) there were no differences, we believe that the increased onset of biliary leak with the second hepatectomy may have corresponded to the fact that we have been expanding the surgical 
Table 3. Evolution

\begin{tabular}{lccccc}
\hline Variable & 1. hepatectomy & 2. hepatectomy & 3. hepatectomy & 4. hepatectomy & p \\
\hline Hospital stay (days \pm SD) & $9.74( \pm 10.046)$ & $9.72( \pm 10.206)$ & $6.10( \pm 1.370)$ & 7.00 & 0.712 \\
Morbidity & $44.35 \%$ & $38.88 \%$ & $10 \%$ & $0.00 \%$ & 0.905 \\
Mortality & $4.34 \%$ & $3.57 \%$ & $0 \%$ & $100 \%$ & 0.001 \\
Biliary fistula & $5.43 \%$ & $10.71 \%$ & $10 \%$ & 0 & 0.922 \\
Abscess & $11.68 \%$ & $14.28 \%$ & $10 \%$ & 0 & 0.912 \\
Incision infection & $8.15 \%$ & $10.71 \%$ & $10 \%$ & 0 & 0.876 \\
Pneumopathy & $4.07 \%$ & $5.35 \%$ & 0 & 0 & 0.772 \\
Hemoperitoneum & $7.06 \%$ & $8.92 \%$ & 0 & 0 & 0.682 \\
Liver failure & $10.86 \%$ & $8.92 \%$ & 0 & 0 & 0.803 \\
Ascites & $8.04 \%$ & $7.14 \%$ & & 0 & 0 \\
SD: standard deviation. & & & 0 & 0
\end{tabular}

SD: standard deviation.

Table 4. Seriousness of complications according to the Dindo-Clavien classification

\begin{tabular}{lccccc}
\hline Variable & 1. hepatectomy & 2. hepatectomy & 3. hepatectomy & 4. hepatectomy & p \\
\hline Type 1 & $8.98 \%$ & $9.25 \%$ & $10 \%$ & 0 & 0.683 \\
Type 2 & $13.48 \%$ & $5.55 \%$ & 0 & 0 & \\
Type 3 & $15.16 \%$ & $20.37 \%$ & $20 \%$ & 0 & 0 \\
Type 4 & $3.37 \%$ & $3.70 \%$ & 0 & 0 \\
Type 5 & $4.34 \%$ & $1.85 \%$ & 0 & & \\
\hline
\end{tabular}

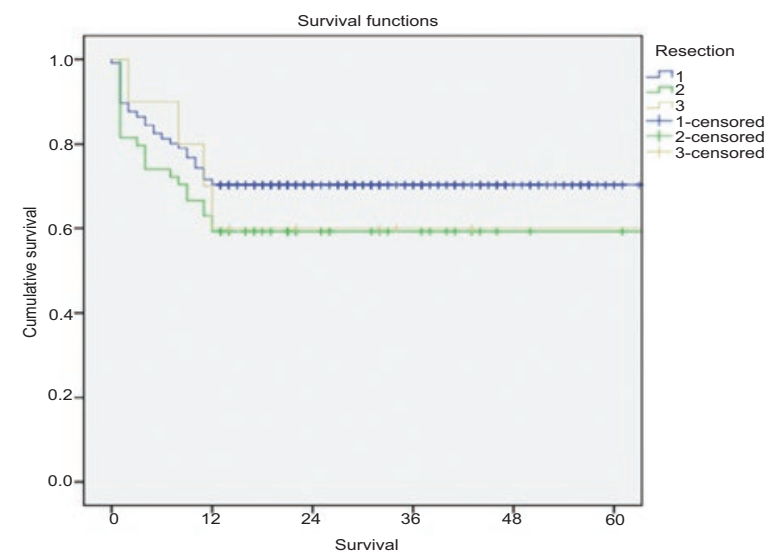

Figure 2. One-year survival.

indications for patients. As mentioned above, there was a significant increase among the re-hepatectomized patients who had more than three metastases and, therefore, a larger compromised surface.

Mortality showed no differences between both groups either. In the repeated hepatectomies, it was $3.5 \%$, which is similar to that reported in other series $^{7,8,13,30-32}$ and confirms, together with the previous data, that repeated hepatectomies have the same short-term results than initial hepatectomy.
Three- and five-year survival rates referred in the literature are disparate, ranging from $21 \%$ to more than $40 \%$. However, according to different authors, there are no differences between the first and subsequent

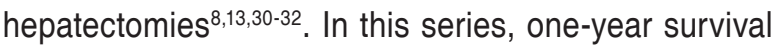
showed no differences between those who underwent one or two hepatectomies ( $p=0.223$ ), whereas three- and five-year survival showed significant differences ( $p=0.024$ and 0.004 , respectively). Patients with relapse considered unresectable have a 5 -year survival rate of $0 \%{ }^{34}$. De Jong et al. ${ }^{1}$ report that those patients who were not resected a second time had a 3 -year survival of $5 \%$. Our results are consistent with those presented by Jones, et al. ${ }^{15}$, who claim that repeated hepatectomy has good results in the short term, but that its long-term effectiveness is marginal. They refer that those patients who were not resected had a survival of 15 months, while those who were did not exceeded 22 months. Our patients had similar results during the first year, but three and five-year survival was low in comparison with other authors, and showed statistical significance when compared with those who underwent one or two hepatectomies. 


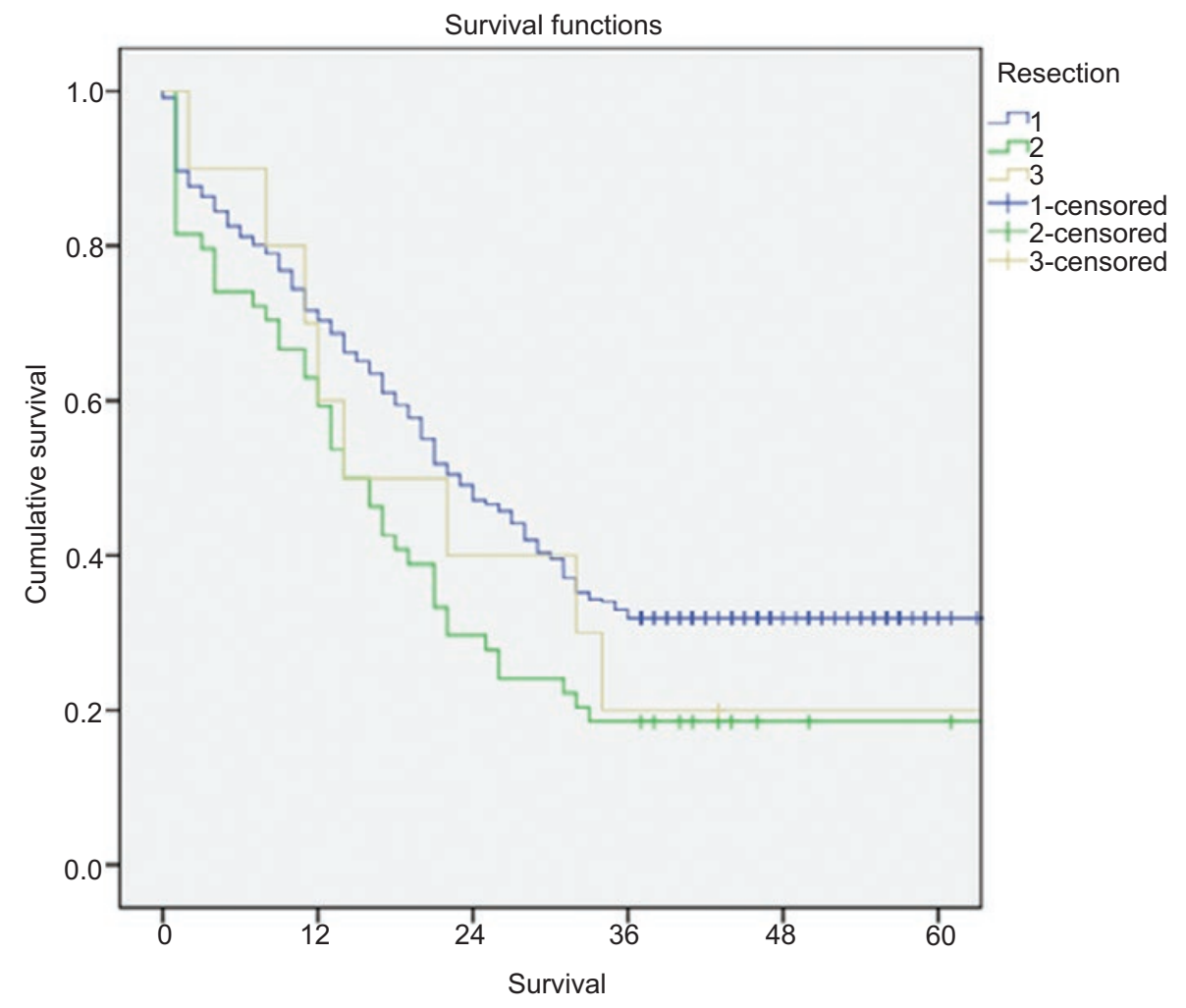

Figure 3. Three-year survival.

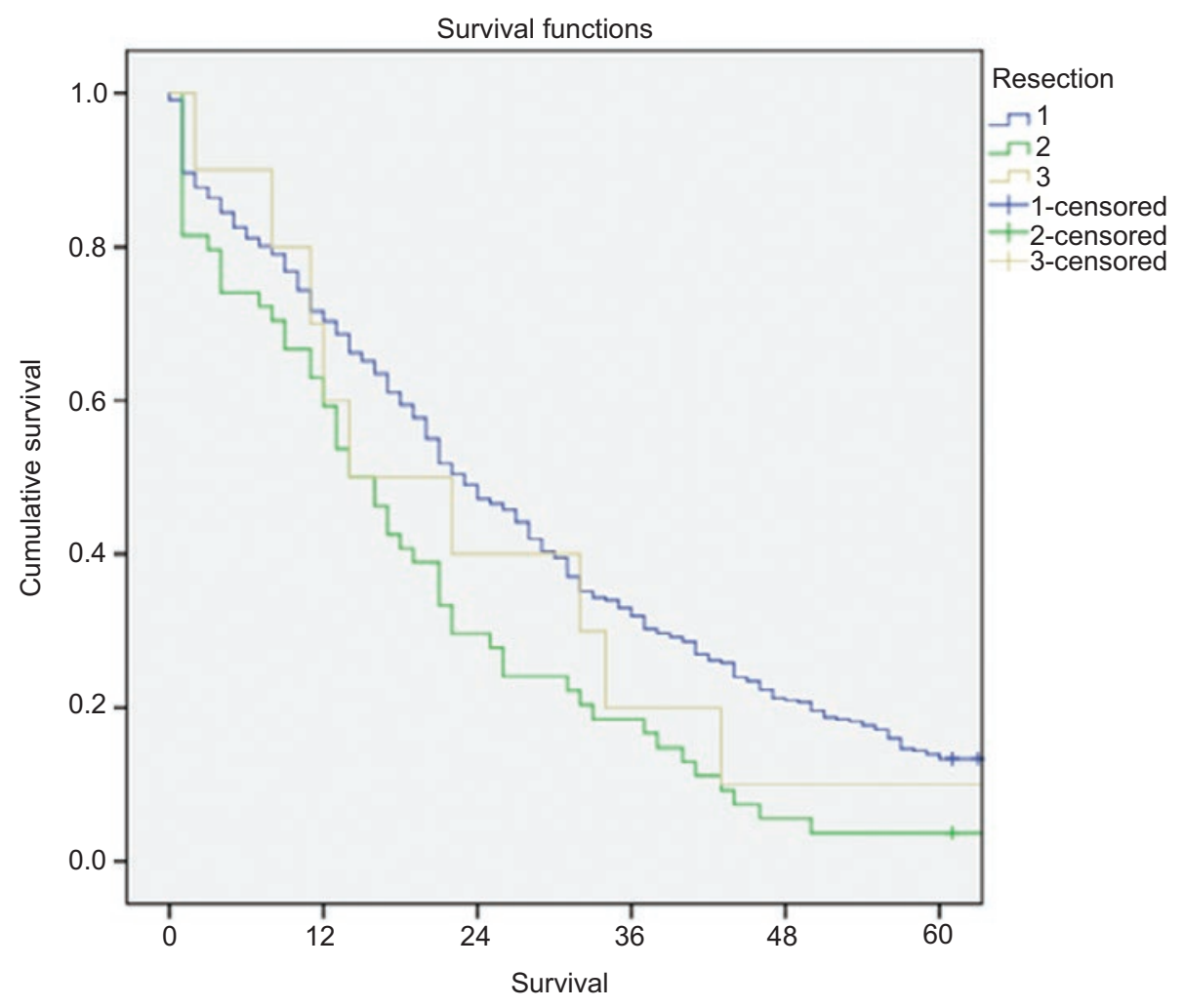

Figure 4. Five-year survival. 
Many factors have been proposed to be of poor prognosis, such as rectal-origin cancer, Dukes $C$, positive lymph nodes on intestinal surgery, transfusions, more than three metastases, bi-lobar localization, resection margin smaller than $1 \mathrm{~cm}$, metastases size larger than $5 \mathrm{~cm}$, major hepatic resection, relapse prior to one year after the first hepatectomy or prior to 6 months, presence of extrahepatic disease, previous liver disease, etc. ${ }^{1,-9,12-15,33,35,36}$. We assessed some of them, and the rectal localization of the primary tumor mentioned by some authors was in this case-series not a factor of poor prognosis, and neither was the presence of extrahepatic disease. Some authors have referred that the presence of positive lymph nodes on intestinal resection has a negative prognostic impact, while others refer that the presence of positive lymph nodes is not a factor of poor prognosis ${ }^{12,33}$. In tumors of the digestive system, it would be important assessing the prognostic impact of the ratio between positive and total lymph nodes referred to in the literature ${ }^{36}$. Bi-lobar localization, major resections, transfusions and presence of liver disease had no direct relationship with poor prognosis either. Some authors ${ }^{8,13}$ report that lesions larger than $5 \mathrm{~cm}$ are a poor prognosis factor; our results show sizes of around $3 \mathrm{~cm}$ on average and have not been identified in the present study as a factor to take into account. A number larger than three lesions is also mentioned in the multivariate analysis as a prognostic factor to consider ${ }^{12}$; although we did not measure it as a predictive factor, we noticed an important increase in the number of patients with more than three metastases in the second hepatectomy $(59.37 \%)$. Classically, a margin of $1 \mathrm{~cm}$ has been considered as a safety margin ${ }^{3}$; in the present series, average margin was smaller than $1 \mathrm{~cm}$, but larger than $5 \mathrm{~mm}$. When we compared if a margin of less than $5 \mathrm{~mm}$ had a negative prognostic impact in comparison with a margin larger than $5 \mathrm{~mm}$, we found that there was no difference $(p=0.057)$. Tanaka et al..$^{14}$ failed to prove that a margin of $1 \mathrm{~cm}$ is necessary to obtain a better prognosis, in agreement with the opinion of other authors ${ }^{9,35}$, who consider that it is actually the execution of an $\mathrm{R} 0$ resection that guarantees a better prognosis. These authors associate $\mathrm{R} 1$ resections with a poor prognosis, although they suggest that current chemotherapy would favor an improvement in long-term results for these patients. Although we have not calculated this variable as a predictive factor, many authors refer that relapse prior to one year after the first hepatectomy is associated with a worse prognosis than when it occurs after one year ${ }^{10,15}$. Ahmad et al.12, in a multivariate analysis found that the appearance of liver injury prior to 1 year after intestinal resection together with having more than three metastases and positive lymph nodes on the colonic resection are of poor prognosis. In contrast, Petrowsky et al..$^{37}$ report that the interval between the first and the second hepatectomy has no influence on prognosis.

In conclusion, we consider that the present work has the limitations of being a series that covers many years, with the consequent differences, as it happens with other series ${ }^{7,33}$. These difficulties make that, despite an important number of publications on the subject, doubts remain concerning the usefulness of repeated resections of liver metastases of colorectal origin. According to our results, second resections have similar results to the first ones in the short term, while long-term results are inferior. Finally, the appearance of new chemotherapeutic agents will favor the expansion of indications for liver resections ${ }^{17,38}$.

\section{References}

1. De Jong M, Mayo S, Pulitano C, Lanella S, Ribero D, Strub J, et al. Repeat curative intent liver surgery is safe and effective for recurrent colorectal liver metastasis: results from an inter-institutional analysis. Gastrointest Surg. 2009;13:2141-51.

2. Bismuth $\mathrm{H}$. Surgical anatomy and anatomical surgery of the liver. World J Surg. 1982;6:3-9.

3. Gonzalez H, Figueras J. Practical questions in liver metastases of colorectal cancer: general principles of treatment. HPB. 2007;9:251-8.

4. Makuuchi M, Takayasu K, Takuma Y. Preoperative trans-catheter embolization of the portal venous branch for patients receiving extended lobectomy due to bile duct carcinoma. J Jpn Surg Assoc. 1984;45:1558-64.

5. Stolz A, Gagniere J, Dupre M, Rivoire M. Destruction locoregionale des metastases hepatiques d'origine colorectale. Place de la radiofrequence. Journal de Chirurgie Viscerale. 2014;151:534-46.

6. De Santibáñez E, Clavien J. Playing play-doh to prevent postoperative liver failure. The "ALPPS" approach. Ann Surg. 2012;255:415-7.

7. Wichters D, De Haas R, Salloum C, Andreani P, Pascal G, Sotirov D, et al. Repeat hepatectomy for recurrent colorectal metastases. Br J Surg. 2013;100:808-18.

8. Adair R, Young A, Cockbain A, Malde D, Prasad K, Lodge J, et al. Repeat hepatic resection for colorectal liver metastases. $\mathrm{Br} J$ Surg. 2012;99:1278-83.

9. Tranchart $\mathrm{H}$, Chirica M, Faron M, Balladur P, Lefevre L, Svrcek M, et al. Prognostic impact of positive surgical margins after resection of colorectal cancer liver metastases: reappraisal in the era of modern chemotherapy. World J Surg. 2013;37:2647-54

10. Tuttle T, Curley S, Roh M. Repeat hepatic resection as effective treatment for recurrent colorectal liver metastases. Ann Surg Oncol. 1997;4:125-30.

11. Grundmann R. Current state of surgical treatment of liver metastases from colorectal cancer. Word J Gastrointest Surg. 2011;27:183-96.

12. Ahmad A, Chen S, Bilchik A. Role of repeated hepatectomy in the multimodal treatment of hepatic colorectal metastases. Arch Surg. 2007;142:526-32.

13. Ishiguru S, Akasu T, Fujimoto $Y$, Yamamoto J, Sakamoto $Y$, Sano T, et al. Second hepatectomy for recurrent colorectal liver metastasis: analysis of preoperative prognostic factors. Ann Surg Oncol. 2006; 13:1579-87.

14. Tanaka K, Shimada H, Ohta M, Togo S, Saitou S, Yamaguchi S, et al. Procedures of choice for resection of primary and recurrent liver metastases from colorectal cancer. World J Surg. 2004;28:482-7.

15. Jones N, McNally M, Malhorta L, Abdel-Misih S, Martin E, Bloomston M, et al. Repeat hepatectomy for metastatic colorectal cancer is safe but marginally effective. Ann Surg Oncol. 2012;19:2224-9.

16. Cai G, Cai S. Multi-modality treatment of colorectal liver metastases. World J Gastroenterol. 2012;18:16-24. 


\section{G. Nari, et al.: Re-hepatectomy as part of multimodal treatment}

17. Adam R, de Gramont A, Figueras J, Guthre A, Korudo N, Kunstlinger F, et al. The oncosurgery approach to managing liver metastases from colorectal cancer: a multidisciplinary international consensus. Oncologist. 2012;17:1225-39.

18. Van der Pool A, Lalmahomed Z, De Wilt J, Eggermont A, ljzermans J, Verhoef C. Local treatment for recurrent colorectal hepatic metastases after partial heatectomy. J Gastrointest Surg. 2009;13:890-5.

19. De Jong M, Pulitano C, Ribero D, Strub J, Mentha G, Schulick R, et al. Rates and patterns of recurrence following curative intent surgery for colorectal liver metastasis: an international multi-institutional analysis of 1669 patients. Ann Surg. 2009;250:440-8.

20. Fong $Y$, Blumgart LH, Cohen A, Fortner J, Brennan M. Repeat hepatic resection for metastatic colorectal cancer. Ann Surg. 1994;220:657-62.

21. Nordlinger B, Vaillant J, Guiguet M, Balladur P, Paris F, Bachellier P et al. Survival benefit of repeat liver resections for recurrent colorectal metastases: 143 cases. Association Francaise de Chirurgie. J Clin Oncol. 1994;12:1491-6.

22. Suzuki S, Sakaguchi T, Yokoi Y, Kurachi K, Okamoto K, Okumura T, et al. Impact of repeat hepatectomy on recurrent colorectal liver metastases. Surgery. 2001;129:421-8.

23. Sugawara G, Isogai M, Kaneoka Y, Suzuki M, Yamaguchi A. Repeat hepatectomy for recurrent colorectal metastases. Surg Today. $2005 \cdot 35 \cdot 282-9$

24. Treska V, Salaicky T, Liska V, Ferda J. Repeated procedures for colorectal liver metastases. Hepatogastroenterology. 2007;54:1775-8.

25. Nishio H, Hamady Z, Malik H, Fenwick S, Rajendra Pasad K, Toogood G et al. Outcome following repeat liver resection for colorectal liver metastases. Eur J Surg Oncol. 2007;33:729-34.

26. Adam R, Bismuth H, Castaing D, Waechter F, Navarro F, Abascal A, et al Repeat hepatectomy for colorectal metastases. Ann Surg. 1997;225:51-62.

27. Strasberg S, Phillips C. Use and dissemination of the Brisbane 2000 nomenclature of liver anatomy and resections. Ann Surg. 2013;257:377-82.

28. Dindo D, Demartines N, Clavien P. Classification of surgical complications. A new proposal with evaluation in a cohort of 6336 patients and results of survey. Ann Surg. 2004;240:205-13.
29. Balzan S, Belghiti J, Farges O, Ogata S, Sauvanet A, Delefosse D, et al. The 50-50 criteria on postoperative day 5: an accurate predictor of liver failure and death after hepatectomy. Ann Surg. 2005;242:824-8.

30. Sa Cunha A, Laurent C, Rault A, Coudere P, Rullier E, Saric J. A second liver resection due to recurrent colorectal liver metastases. Arch Surg. 2007;142:1144-9.

31. Pessaux $P$, Lermite $E$, Brechant $O$, Tuech J, Lorimier G, Arnaud J. Repeat hepatectomy for recurrent colorectal liver metastases. J Surg Oncol. 2006;93:1-7.

32. Muratore A, Polastri R, Bouzari H, Vergara V, Ferrero A, Capussotti L. Repeat hepatectomy for colorectal liver metastases: a worthwhile operation? J Surg Oncol. 2001;76:127-32.

33. Nagakura S, Shirai Y, Suda T, Hatakeyama K. Multiple repeat resections of intra and extra-hepatic recurrences in patients undergoing initial hepatectomy for colorectal carcinoma metastases. World J Surg. 2002;26:141-7.

34. Kin T, Nakajima $\mathrm{Y}$, Kanehiro $\mathrm{H}$, Hisanaga M, Ohyama T, Nishio K, et al. Repeat hepatectomy for recurrent colorectal metastases. World J Surg. 1998:22:1087-91.

35. Khan S, Matthews J. Intraoperative margin re-resection for colorectal cancer liver metastases. Hepatobiliary Surg Nutr. 2013;2:108-2.

36. Nari G, Palacios O, López Ben S, Albiol M, Falgueras L, Castro Gutiérrez E, et al. Hilar cholangiocarcinoma: the number of positive nodes and positive node/total node ratio is a significant prognostic factor for survival. Cir Esp. 2014;92:247-53.

37. Petrowsky H, Gönen M, Jarnagin W, Lorenz M, DeMatteo R, Heinrich S, et al. Second liver resections are safe and effective treatment for recurrent hepatic metastases from colorectal cancer: a bi-institutional analysis. Ann Surg. 2002;235:863-71.

38. Figueras J, Torras J, LLadó L, Ramos E, Martí-Rogue J, Serrano T, et al. Surgical resection of colorectal liver metastases in patients with expanded indications: a single center experience with 501 patients. Dis Col Rectum. 2007;50:478-88. 